\title{
Advanced system based on ontology and multi agent technology to handle upstream supply chain: intelligent negotiation protocol for supplier and transportation provider selection
}

\author{
Iman Achatbi ${ }^{\text {a*}}$, Khalid Amechnoue ${ }^{\mathrm{a}}$, Tarik EL haddadi ${ }^{\mathrm{b}}$, and Saloua Aoulad Allouch ${ }^{\mathrm{a}}$
}

${ }^{a}$ Mathematics, Informatic \& Applications Team, National School of Applied Sciences, Abdelmalek Essaadi University, BP 1818 Tangier, Morocco

${ }^{b}$ Natural Risk Research Team, Faculty of Science and Technology, Abdelmalek Essaadi University, BP 1818 Tangier, Morocco

\begin{tabular}{l} 
C H R O N I C L E \\
\hline Article history: \\
Received February 23, 2020 \\
Received in revised format: \\
March 29, 2020 \\
Accepted April 232020 \\
Available online \\
April 23, 2020 \\
\hline Keywords: \\
Supplier selection \\
Transportation \\
Multi-agent systems \\
TOPSIS \\
AHP \\
Ontology
\end{tabular}

\section{Introduction}

Nowadays, the globalization and the evolution of organizations spawn new challenges and risks for companies. To face these changes, collaborative work between all actors in the supply chain is required. Stakeholders involved in the supply chain modify their behaviours to adapt to market and competition evolutions. Besides, satisfying market demand on time and with right quantity is considered as one of the principal factors in upholding the competitive advantage in the market. Among supply chain management problems, supplier selection is one of the wide studied issues in the literature, seen its direct impact on the whole supply chain. Supplier selection is the process by which suppliers are reviewed, evaluated, and chosen to become part of the company's supply chain (Sanayei et al., 2010). In a majority of companies, materials and components supplied constitute $60 \%$ to $70 \%$ of the manufactured products costs. Thus, reducing procurement costs involve reducing finished products costs, and then having more financial margins. Choosing right suppliers involves much more than scanning a series of price list, and choices will depend on a wide range of factors which involve both quantitative and qualitative criteria (Ho et al., 2010), such as price, time and quality; it is extremely

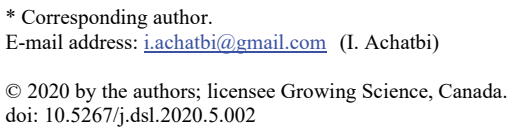

\begin{abstract}
In the existing market, companies confront a fierce competition, so the need for new and efficient process for supply chain has become necessarily important. To this end, supply chain process related to the inbound logistics. However, most of recent systems deal solely with the negotiation including the selection of one or multiple suppliers, without supporting the transportation provider selection simultaneously and consider it as decision criterion that affect
the final choice of cooperative suppliers. As part of win-win negotiation, active supplier involvement can enhance efficiency and effectiveness of supply chain. Then again, transport cost To face this challenge, a new form of supplier selection including transportation provider this purpose, we present a multi-issue decision protocol based on multi agent system. Furthermore, the automated multi-criteria analysis model based on combined analytical hierarchy process (AHP) and TOPSIS is judged helpful for decision-makers to make quick decision with less human interactions.
\end{abstract}

(1) 
difficult to find a supplier who excels everywhere. Otherwise, the issue of choosing a single supplier or sharing the offer between several suppliers has been widely handled in the literature; both of them have advantages and inconveniences. In mono sourcing approach, supplier and manufactory can participate in a synchronization of production and delivery systems, which reduces the inventories (Chiang \& , 1996). However, manufactories are upholding, in the most general case, the strategy with several suppliers and this strategy may involve sharing the order between several suppliers, which reduces uncertainty about delivery times, storage costs and the risk of stock outs (Ram, 1999; Ho et al., 2010)). On another side, Transportation service is considered as the indispensable trait union between all stakeholders involved in the Supply Chain. Moreover, transport cost constitutes the most important factor in the third of the total operational costs of a supply chain. In terms of economic organization, some companies still choose to work with their own fleets or rented vehicles to keep costs under control. In this case, the problem of returns profitability is involved. This is referred to as own-account transport. But a large part of transport is provided by specialised companies that offer high level services and we speak about transport for hire or reward. Freight can be transported using truck-load (TL) or less-thantruckload (LTL). Less-than-truckload shipping is exploited in case of shipping smaller freight loads, while truckload shipping, is for cargo that fills the entire trailer. TL rates are usually stated on a per mile basis and LTL rates are generally stated per hundred weight (CWT) for a given origin and destination (Swenseth \& Godfrey, 2002).

Less-than-Truckload (LTL) Shipment

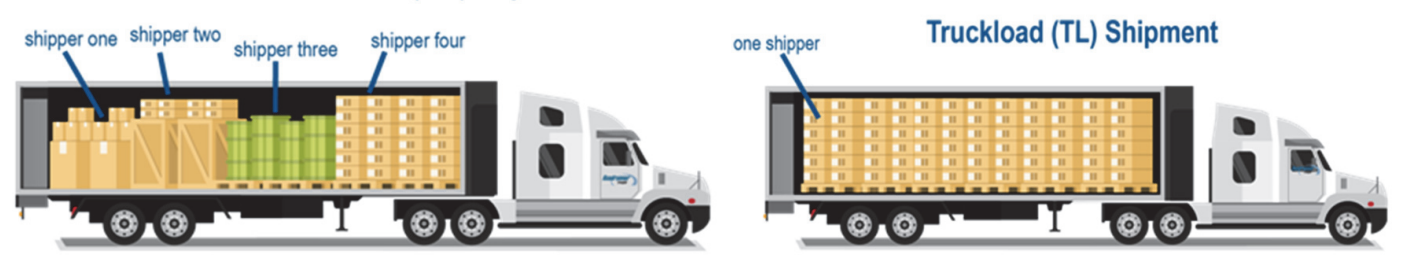

Fig. 1. LTL versus TL transport

More and more, multi agent systems are perceived as a promising technology to improve and replace technologies used in transactional and analytical data flow, especially in industry 4.0. The ability to negotiate and collaborate is the powerful features of agents that distinguish them from other software. In fact, agents are best suited for applications that are decentralized, so it is the most appropriate solution to schematize the supply chain; each node is represented by one or many agents. Basically, software agents equipped with negotiation knowledge are supposed to interact and negotiate autonomously on behalves of their owners. Besides, ontology provides machine readable and understandable domain knowledge and play an important role in knowledge representation, so it is a propitious solution to assist agent reasoning ability. According to the ontology structure, inference rules can be defined to conduct agents' negotiation behaviours to adapt to various negotiation environments (Wang et al., 2013). In fact, existing agent-based negotiation models for supplier selection focus only on the decision criteria such as cost, quality, delivery time and the like. But, few studies have explicitly addressed the role of transport in the issue of supplier selection in supply chain design and management, which is an important limitation. Indeed, sharing demand between several suppliers involves significant transport costs of up to $30 \%$ of the total logistics cost (Thomas et al., 1996; Stank \& Goldsby, 2000b), which is extremely cumbersome for the manufactory and the suppliers. So, this paper aims to provide three genuine contributions:

- This work is particularly interested in the problem of supplier selection and treats transportation provider selection explicitly and simultaneously, by proposing an agent-based negotiation model,

- We initiate for this purpose two ontologies to conduct the bilateral negotiation between the buyer side (plant) and seller side (suppliers and transportation providers), 
- Finally, the proposed framework employs the negotiation protocol and AHP-TOPSIS method to rank the potential suppliers to decide either to arrange the transportation by the supplier or outsource it to a transportation provider.

The rest of the paper is organized as follows. Section 2 reviews literature on supplier selection, agentbased negotiation models and ontology-based approach for multi-agent system. The description of the problem is proposed in Section 3. Section 4 portrays the multi agent system architecture adopted to automate the supplier selection process and transport provider selection process and reveals the negotiation protocol between agents. Section 5 specifies the computational elements in the proposed model. Section 6 demonstrates the function and effectiveness of the agent-based negotiation and shows the principal results. Finally, conclusion and future work follow in Section 7.

\section{Literature review}

\subsection{Supplier and transport evaluation and selection}

Supplier selection has received considerable attention for its significant effect toward successful logistics and supply chain management. In contemporary supply chain management, the performance of potential suppliers is evaluated against multiple criteria rather than considering a single factor - cost, it is abstracted as a multi-criteria decision-making (MCDM) problem that analyses and measures the performances of a set of suppliers on multiple selection criteria by decision making methods(De Boer et al., 2001). Ho et al. (2010) analyzed multi criteria decision making (MCDM) approaches for Supplier selection based on journal articles from 2000 to 2008, Eventually, Cha et al. (2013) provided a literature review in the developments of supplier selection that have emerged from 2008 to 2012. Predominately, research on supplier selection problem focuses on supplier selection criteria, criteria weight determination methods and supplier evaluation methods, such as analytic hierarchy process (AHP)(Chan \& Chan, 2010; Ishizakan et al., 2012), analytic network process (ANP) (Sarkis \& Talluri, 2002; Gencer et al., 2007), case-based reasoning (CBR)(Choy \& Lee, 2002; Choy \& Lee, 2003; Choy et al., 2005), data envelopment analysis (DEA)(Wu \& Blackhurst, 2009), fuzzy set theory (FlorezLopez, 2007), genetic algorithm (GA)(Ding et al., 2005; GüNeri et al., 2011), mathematical programming(Talluri \& Baker, 2002; Lin et al., 2011), simple multi-attribute rating technique (SMART)(Huang \& Keskar, 2007; Sachan \& Datta, 2005), and their hybrids.

In fact, the literature review cited above revealed that transportation is implicitly indicated in the criteria related to the total cost of the product, delivery time and geographic location of suppliers. However, in different approaches used in the literature, transport is rarely explained; this is an important limitation. Indeed, sharing demand between several suppliers involves significant transport costs of up to $30 \%$ of the total logistics cost (Thomas \& Griffin, 1996; Stank \& Goldsby, 2000a), which is extremely cumbersome for the purchasing company or the supplier. The main research on transport and its role in the process of supplier evaluation and selection are: Hong et al. (1992) studied procurement strategies in a JIT environment and proposed a non-linear mathematical program aimed to minimize aggregate storage and ordering costs, under shipping cost and quality constraints. Tyworth (1991) examined explicitly the role of transportation in the case of single-supplier procurement compared to the use of two suppliers. A model minimizing the sum of purchase, order, transport and storage costs is developed.

\subsection{Agent based negotiation models}

Multi-agent technology has been largely used in many areas but industry applications have taken the earliest advancement of agent technology when compared to others. According to Wooldridge and Jennings (1995) "an agent is a computer system that is situated in some environment, in which it is capable of autonomous action, in order to meet its predefined objectives"'. In industry area, the two major focusing points on automated negotiation are the negotiation protocols and agent decisionmaking models. As an example of decision-making models: model that automates the supplier selection process. Wang et al. (2009) proposed an agent-mediated coordination approach to automate the supply chain formation in dynamic and uncertain environments. Nejma et al. (2019) proposed a multi agent 
negotiation protocol supporting the supplier selection under consideration of dyadic collaboration between suppliers and customers. Recent awareness and advancements in sustainable supply chain management (SSCM) has motivated many researchers and industrial practitioners to practice the integration of sustainability Triple Bottom Line (TBL) attributes (environmental, economic and social) in production and supply chain activities of manufacturing organizations (Giret et al., 2018; Ghadimi et al., 2018). Besides, The study of Yu et al. (2018) handled the environmental criteria in the process of supplier selection, they propose a hybrid sustainable supplier selection approach integrating compensatory and non-compensatory decision rules, using TOPSIS and ELECTRE. Wang et al. (2012) established a MAS platform for individual companies to form an ecological virtual enterprise based on ontology theory and intelligent agents. An automated negotiation model for e-commerce decision making is proposed by Cao et al. (2015). Regarding the study conducted by (G. Wang et al., 2013), they focus on the problem of supplier selection, as a promising technology to present complex knowledge and reasoning about them, they use an ontology-based approach to organize the multi agentassisted supply chain negotiations. Wang et al. (2014) proposed a hybrid multi-agent negotiation protocol to regulate the mobile agent-assisted negotiation, and embedded an ontology operation protocol in it to govern negotiation knowledge. Yu and Wong (2015a) and Yu and Wong (2015b) attempted to adopt agent-based negotiation model to solve multi product supplier selection problem but the negotiation protocol special for multi-product environment has not been focused on.

Researchers have proposed different negotiation protocols to govern the interaction of agents involving in supplier selection process. Bilateral and multilateral agent negotiation protocols have been proposed in e-procurement and supply chain order fulfilment negotiations, based on the CNP (Contract Net Protocol) regulation (Lin \& Lin, 2006; Renna \& Argoneto, 2010). The buyer and seller bargain iteratively on multiple negotiation issues using the buyer-seller bilateral negotiation protocol (Talluri, 2002). Adopting this protocol, agents' decision making methods are studied using the genetic algorithms (Choi et al., 2001), the heuristic negotiation concession functions(Narayanan \& Jennings, 2005), the incomplete information inference (Jonker \& Treur, 2007), or the constraints-based fuzzy rules (Chen \& Huang, 2009).

\subsection{Ontology based approach for multi agent system}

Any reliable decision-making model needs a wealth of information on the background that sustains the evaluation process. It is beneficial to use data management tools to manage a massive amount of information. Ontology is a tool designed to represent concepts, store domain knowledge and exchange knowledge-level messages. Furthermore, ontologies provide a suitable platform for agents and human communications. To facilitate dynamic negotiation behaviours and to enable agent to dynamically adapt their negotiation behaviours to specific negotiation situations, logical rules must be integrated in the inference part of agent. The negotiation knowledge is structuralized as terms in the negotiation ontology, described through specific attributes. The direct and indirect relations between the terms are constructed as logical rules on top of the ontology architecture. In recent researches, ontology has been adopted to represent the negotiation protocol and make agent adapt to various negotiation mechanisms.

Tamma et al. (2005) presented an ontological approach for automated negotiation, particularly suited to open environments. In their work, the negotiation protocol is defined in terms of shared negotiation ontology instead of being hard-coded within agents. Giovannucci et al. (2008) extended the ontology presented by Tamma et al. (2005) to facilitate multi-item, multi-unit combinatorial reverse auctions. Sadigh et al. (2017) developed a multi- agent hybrid partner selection algorithm for application in the development of an ontology-based multi-agent virtual enterprise (OMAVE) system.

\section{Description of the problem}

Indeed, the problem of supplier selection is largely studied in the literature, but little attention is given to the transportation aspect as criterion in this decision. Current studies indicate that buyers can improve lead-time performance and reduce total inventory-system costs by splitting orders between several suppliers. These studies, however, treat transportation only implicitly as an element of the cost of 
placing an order. This is an important limitation, because shipping costs increase excessively as the size of shipment decreases and typically comprise a sizeable portion of total logistics cost. Moreover, component category is crucial criterion in the process of transportation selection seen that some sensitive products require a specific environment like warm weather, low humidity, low temperature degree and so one. Therefore, transportation provider selection must be based on, among others, the category of raw material transported.

In order to generate cost reductions and value chain optimization, the purchasing company must proactively manage its purchases and establish close relationships with a network of efficient and reliable suppliers, on the one hand, and organize its freight transport network along its supply chain, on the other hand. Thus, transportation criterion plays a critical role in the supplier selection decision, it impact the total logistics cost and the current treatment of transportation can often lead to wrong decision.

In this paper, we are particularly interested in the problem of supplier selection and treat transport provider selection explicitly and simultaneously. The proposed system consists of a manufacturing facility that procures raw material from a set of potential suppliers. The agent-based negotiation model is therefore a one-to-many negotiation model. To be mentioned that the demand placed on the manufacturer must be satisfied by the selected suppliers without shortages and the capacity at the manufacturer is assumed to be infinite while suppliers have finite capacity and procure items (e.g., raw materials) at different purchasing costs and quality levels. That is to say, we adopt a set of criteria to evaluate suppliers: cost, quality and time. In this article, the transportation cost is modelled using TL and LTL rates (Mendoza \& Ventura, 2013). As noted by Swenseth and Godfrey (2002), this assumption is practical given the fact that in today's market many factors are driving the use of small shipment sizes (LTL), including an increasing number of stock-keeping-units driven by greater demand for product customization, lean philosophies, and the resulting push to more frequent shipments.

Accordingly, the selection of transportation providers goes through two essential phases: the first phase is a pre-selection phase which defines transporters respecting requirement asserted by the suppliers, second phase focuses on the selected transportation provider respecting a list of criteria, we essentially consider in our work, price and delivery time.

\section{Multi agent system architecture for supplier selection and transportation provider selection}

The aim of the agent-based model is to support the negotiation between the manufacturing facility, suppliers and transportation providers simultaneously. As it involves one buyer (purchasing company), many suppliers, and many transportation providers, the multi agent system is one-to-many multi-issue negotiation model.

\subsection{Multi-agent system archtecture}

The conflicting objectives are to minimize total costs on the entire chain, and to maximize a combined value of overall equipment effectiveness from suppliers. The proposed solution will be able to model complex system for supply chain management to address the issues of communication among the upstream parties involved in supply chain, it consists of: Coordinator Agent, procurement agent, Seller Agent, Transport Product Agent, in purchasing company; Supplier Agent, Material Seller Agent, Transport Supplier Agent in supplier node; and finally, in the transport service node, the transport agent is present (Table 1). Simultaneously, TransportProduct agent prompts the negotiation with Transport Agent to insure transportation of raw materials from suppliers to the warehouse in production node. The outputs of TransportProduct Agent are supplier localization, product type and dimension, quantity, and delivery time. 


\section{Table 1}

Multi agent system architecture for supplier selection and transportation provider selection

\begin{tabular}{|c|c|c|}
\hline \multicolumn{3}{|c|}{ Proposed agents for the negotiation } \\
\hline Label & Agent & Activities \\
\hline $\mathrm{CA}$ & Coordinator Agent & $\begin{array}{l}\text { - Controls the interaction between other agents; } \\
\text { - Creates PA for each SpA; } \\
\text { - Creates TPA for each TA; } \\
\text { - Selects the cooperative suppliers and transportation providers. }\end{array}$ \\
\hline SA & Seller Agent & - Determine the set of required products. \\
\hline PA & Procurement Agent & $\begin{array}{l}\text { - Receives command from CA about the amount of product must be bought, } \\
\text { - Deals with SpA about cost, quality and time. } \\
\text { - Conducts bilateral bargaining with supplier agent }\end{array}$ \\
\hline TPA & $\begin{array}{l}\text { Transport Product } \\
\text { Agent }\end{array}$ & $\begin{array}{l}\text { - Receives command from CA to search transportation providers from supplier to } \\
\text { purchasing company, } \\
\text { - Agrees with the TA about price and delivery time. } \\
\text { - Conducts bilateral bargaining with supplier agent }\end{array}$ \\
\hline TA & Transport Agent & $\begin{array}{l}\text { - Represents transportations providers in the bilateral bargaining process and deals } \\
\text { with the corresponding TPA. }\end{array}$ \\
\hline TRpA & $\begin{array}{l}\text { TransportPlanning } \\
\text { Agent }\end{array}$ & • Have knowledge about transport planning. \\
\hline SPA & Supplier Agent & $\begin{array}{l}\text { - Represents supplier in the bilateral bargaining process and deals with the } \\
\text { corresponding PA. }\end{array}$ \\
\hline MsA & $\begin{array}{l}\text { Materiel supplier } \\
\text { Agent }\end{array}$ & - Have knowledge about the stock of material \\
\hline
\end{tabular}

To ensure process production of finished goods, timely coordination of the elements of orders with suppliers is required, namely lists of materials needed, their quantity, price, time and quality.

Seller agent cheeks the database of finished goods and database of raw materials, it sends an order to the coordinator Agent to buy raw material if stock is insufficient. CoordinatorAgent commands Procurement Agent to buy raw materials, the last one agrees with Supplier agent about price, quality and delivery time (Fig. 2)(Achatbi et al., 2017).
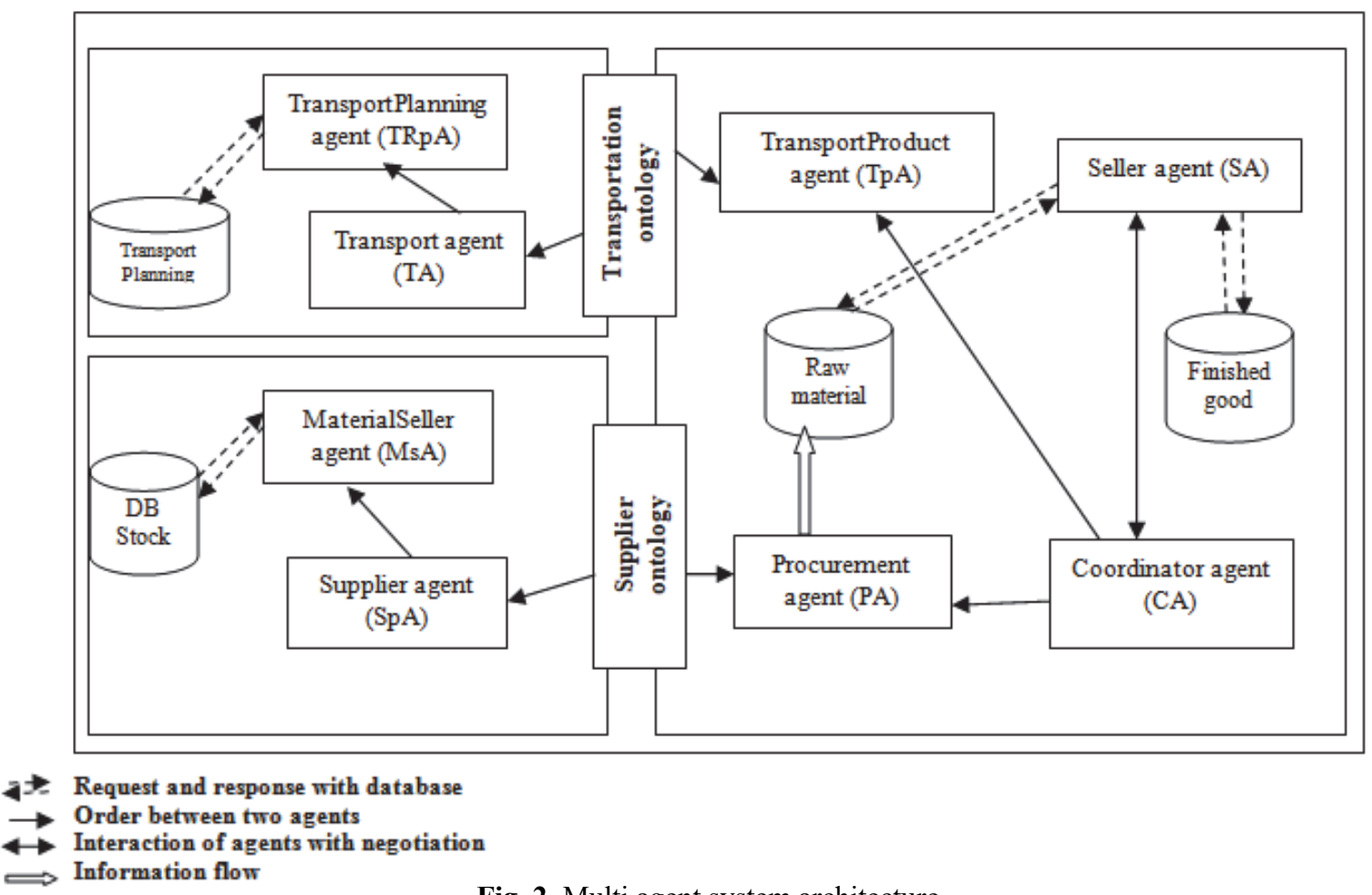

Fig. 2. Multi agent system architecture 


\subsection{Negotiation protocol}

Existing multi-agent negotiation protocols do not support supplier selection and transportation provider selection simultaneously. However, in practice, it is crucial for the purchasing company to consider the transport service as criterion in the supplier selection. Therefore, a multi-agent negotiation protocol appropriate to the supplier and transportation selection problem should be extended. Regarding the onebuyer-many-seller negotiation model, the buyer is represented by multiple PA instances initialized by the CA to negotiate with respective sellers represented by SpAs for supplier selection and TAs for transportation provider selection. Through iterative negotiation concessions, each pair of PA instance and SpA generates a negotiation result and each pair of TA and TpA respectively. The CA then collects all the negotiation results and selects the preferable combination of suppliers and transportation providers (Fig. 3). Firstly, the seller agent checks databases of raw materials and finished products in order to determine the type and amount of raw materials to buy.

Then, the coordinator agent receives the order from seller agent to buy raw material, with specific type and quantities. It creates instances of the procurement agent PAs for all suppliers, and transport product agent TPAs for all transportation providers.

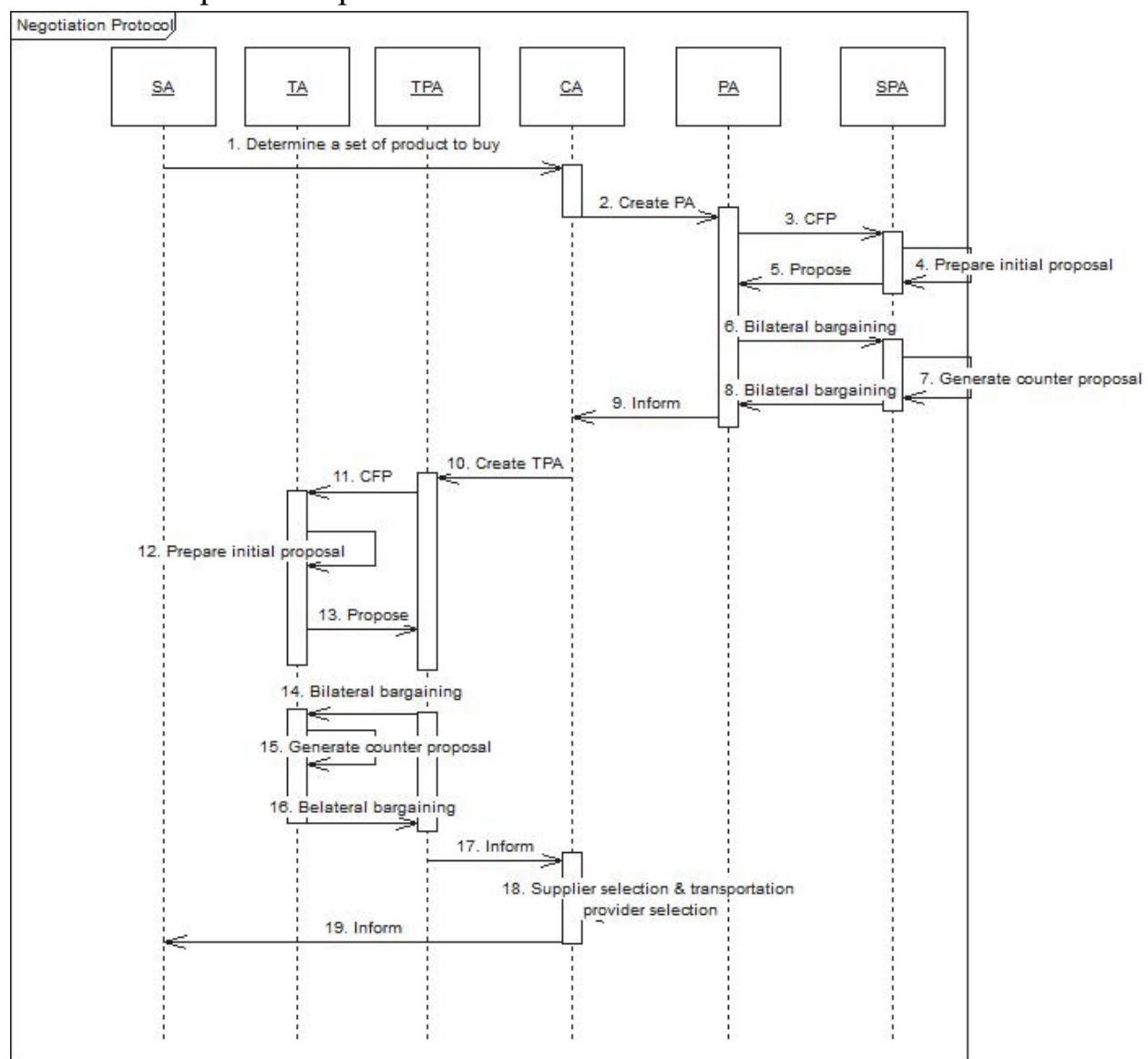

Fig. 3. Negotiation protocol for selecting suppliers \& transportation providers

Regarding the Procurement agent, it conducts the bilateral bargaining with the corresponding SPA. The negotiation is about price, quantity, quality, time. Then after, the transport product agent conducts the bilateral bargaining with the corresponding TA, the negotiation is about shipment cost and delivery time. Finally, the CA selects cooperative suppliers and corresponding transportation providers to procure required components, based on the negotiation results between the PA and the SpAs and TpAs and TAs accordingly. The message exchange for the negotiation takes the form of alternate and iterative exchanges of "call for proposal (cfp)" and "propose" messages. 


\subsection{Negotiation ontology}

The principal goal in considering the ontology is to create a usable description of what is known about a domain. Restricted reasons reflect the development of ontology, notably to share common understanding of the structure of information among people or software agents or to enable reuse of domain knowledge and make domain assumptions explicit. In our case, we create negotiation ontology to normalize the negotiation process between different part of upstream supply chain, on one side the purchasing company and suppliers, and on the other side the purchasing company and transportation providers. For this purpose, two aspects have to be considered when organizing negotiation knowledge through ontology. The first is to solve the ontology interoperability problem in agent communication. The second is to build separated negotiation ontology to facilitate negotiation behaviour deployment and to respect the data confidentiality in the different parts. For this purpose, we opted to create tow separated ontology, Supplier Ontology and Transportation Ontology. To point up functional requirements to be respected in the elaboration of that ontology, a set of competency questions is used. The following list highlights some competency questions used in the elaboration of our ontology:

1. Dimension specifications: is the product small? What is the height of the product? What is the width?

2. Sensitivity considerations: what is the low temperature required? What is the high temperature required? What is the low humidity required? What is the high humidity required?

3. Fragile and special handling requirements: is the product dangerous good? Can it be shipped next to another product? What are the incompatible products not to be shipped with?

Fig. 4 highlights the UML diagram of the ontology negotiation between the purchasing company and suppliers in order to make a compromise about the quantity of raw material to provide and deadline to respect. Under the Concept schema, the Product Concept describes the type of product to procure, object of the bilateral negotiation; this class have a reflexive object property incompatibleProduct to represent products that mustn't be transported with the product procured, owing to the product sensitivity. IssueNegotiation is used to portray the value of the negotiation items which may be quantitative issues or qualitative issues, for example, price of the component, quality and time. Moreover, the class Requirement involves all information needed to transport product in a good condition such as: high and low temperature allowed, max humidity and min humidity. Finally, Seller Concept highlights the descriptive details of the supplier.

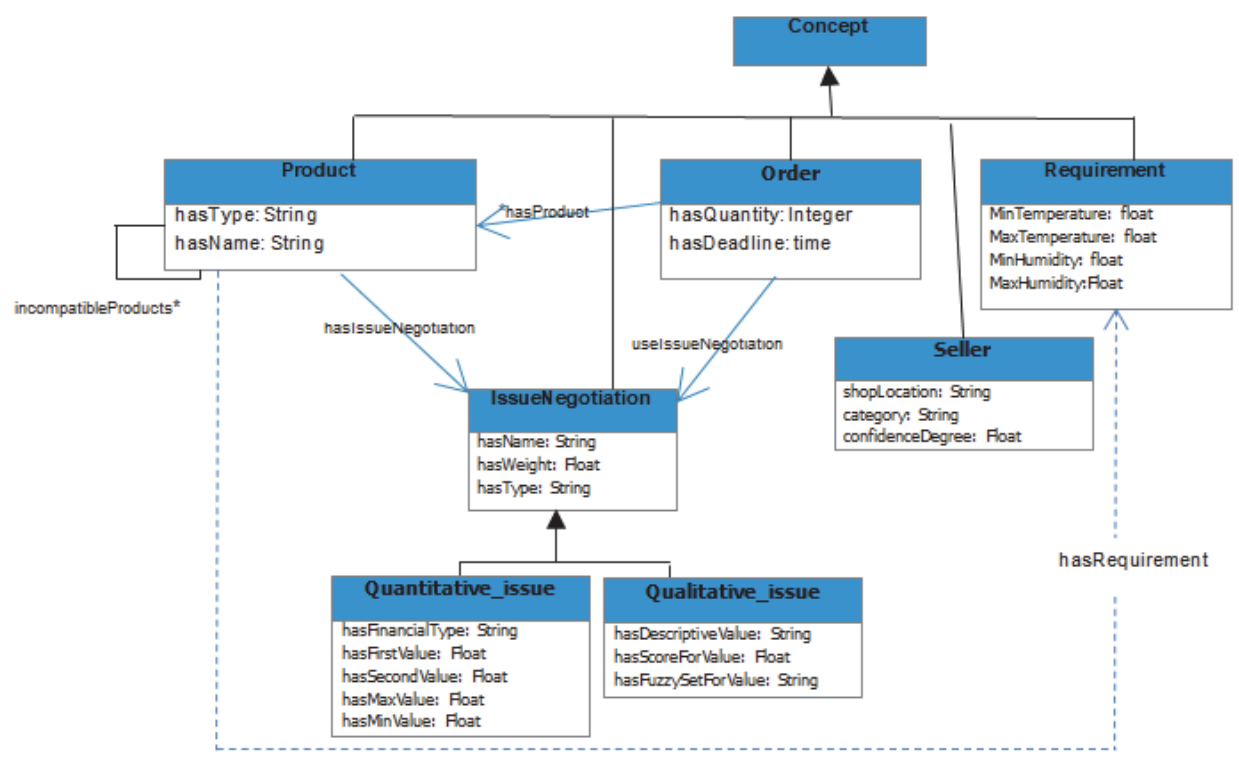

Fig. 4. UML diagram of supplier ontology 
To select suitable transport equipment and shipping containers, synchronization between supplier selection process and transportation provider evaluation process must be treated together. To ensure that raw materials can be safely transported within the transport temperature profile defined for each product and humidity required, in order to protect product against degradation. We initialize for this purpose transportationOntology, to conduct the bilateral bargaining between the manufactory and different transportation providers as figured in Fig. 5.

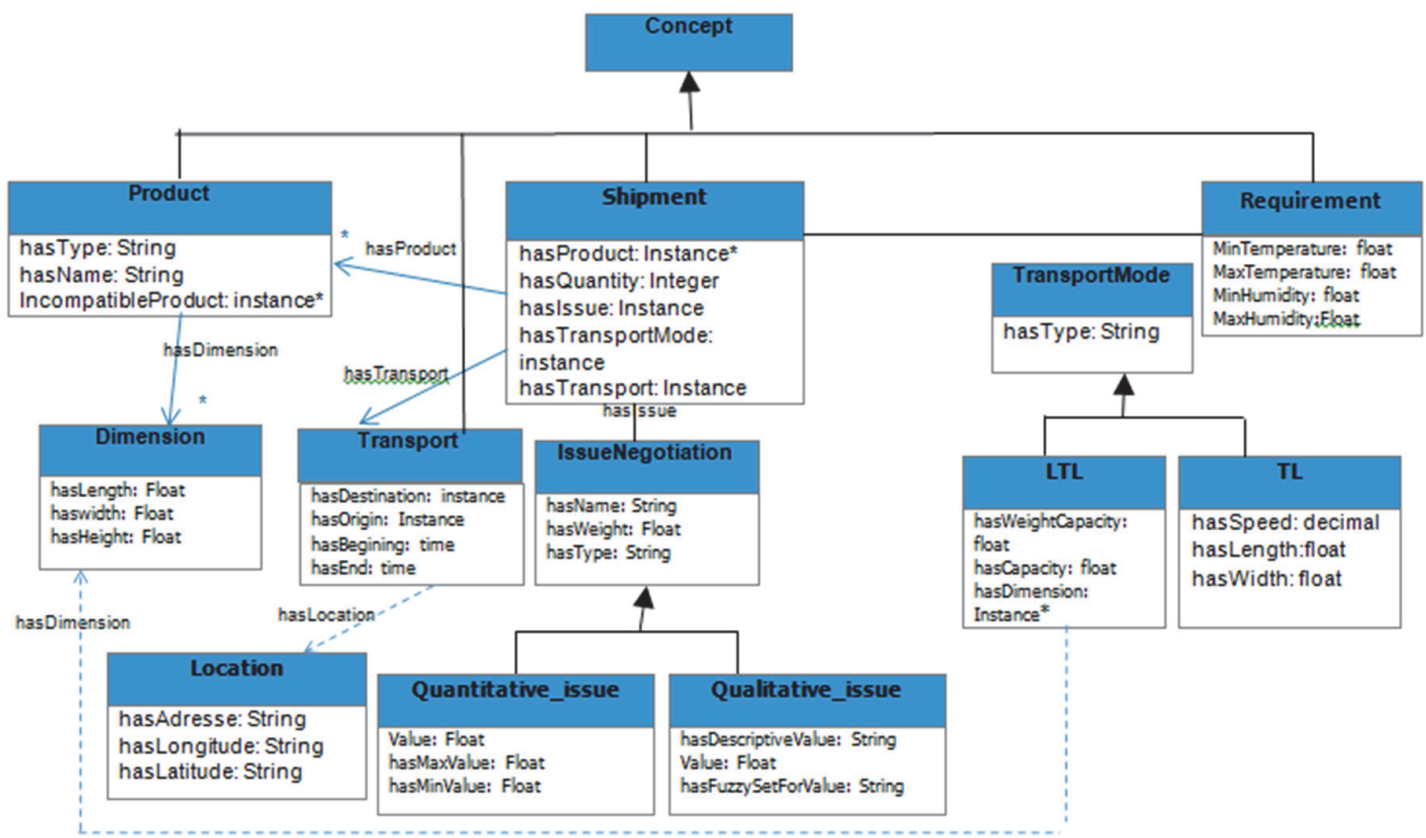

Fig. 5. UML diagram of transportation ontology

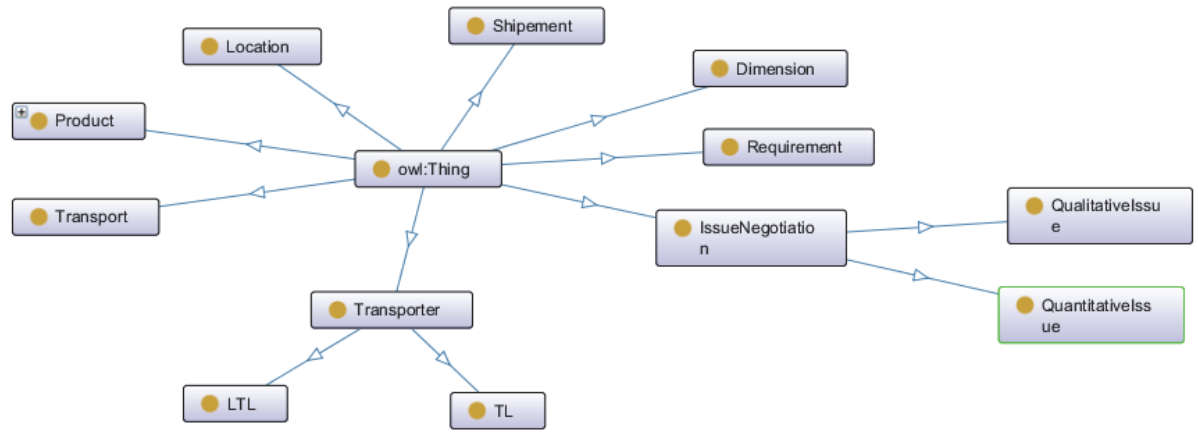

Fig. 6. transport ontology illustration

\section{Conputational elements of the proposed model}

\subsection{Negotiation model procedure}

The proposed negotiation model consists of three phases: supplier bilateral bargaining, transportation provider bilateral bargaining and cooperative supplier and transportation provider combination Fig. The functions of the three phases are explained as follows.

Phase 1: supplier bilateral bargaining

The objective of this phase is to make a deal with diverse cooperative suppliers to procure raw materials. During the negotiation process, the PAs and SAs exchange proposals to bargain over a product. Within the tolerable negotiation time (i.e. negotiation deadline is not reached), the agent can evaluate the proposal/counter-proposal proposed by the opponent. The agent can accept the offer, or reject it and generate a counter-proposal. 
Phase 2: transportation provider pre-selection

After dealing with different suppliers about products to procure, the following step is to determine the pre-cooperative transportation providers assuring the shipment. The TPAs and TAs exchange proposals to negotiate about the transport means proposed, either LTL or TL and the product transportation conditions. In this phase, the selection of short list transportation providers is based on the product requirement satisfaction. For this purpose, the transportationOntology is initialized.

Phase 3: transportation provider bilateral bargaining

Afterward, the TPAs bargains with different TAs. The negotiation is about the cost of shipment and the delivery time. Within the tolerable negotiation time (i.e. negotiation deadline is not reached), the agent can evaluate the proposal/counter-proposal proposed by the opponent. The agent can accept the offer, or reject it and generate a counter-proposal.

Phase 4: supplier and transportation provider combination

In this phase, the CA receives different results from the bilateral bargaining phases, the principal goal of this phase is to select the cooperative suppliers and transportation providers based on the final offers submitted by each part, and to compose the best suitable combination of suppliers and transportation provider to ensure the procurement of raw material in the purchasing company warehouses with the optimal values.

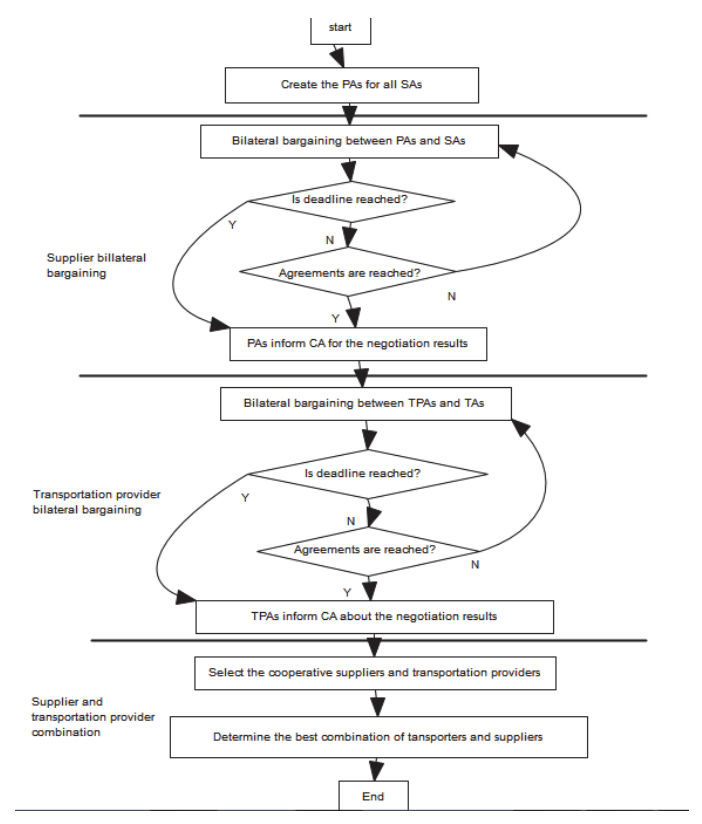

Fig. 7. Negotiation model procedure for supplier and transportation provider selection

\subsection{Normalization of the problem}

The manner of selecting the right suppliers and partners is considered as key issue for Supply Chain. For this purpose, we adopt a hybrid multi-criteria decision method for inbound logistics decision making. We exploit the AHP method to analyze the structure of the supplier and transportation selection problem and determine the criteria weights, and we use TOPSIS method for final ranking. In short, AHP is a method to derive ratio scales from paired comparisons. In the Analytic Hierarchy Process, the relative importance of the component or criterion $i$ in relation to component $j$ is determined using the Saaty scale and is assigned to the $(\mathrm{i}, \mathrm{k})^{\text {th }}$ position of the pairwise comparison matrix. Automatically, the inverse of the assigned number is associated with the $(\mathrm{k}, \mathrm{i})^{\text {th }}$ position according to the following rule (Chang et al, 2007): 


$$
a_{i k} \succ 0, \quad a_{i k}=1 / a_{i k}, \quad a_{i i}=1 \forall i
$$

Regarding the TOPSIS method (Technique for Order Preference by Similarity to Ideal Solution), it is used to rank different alternatives by measuring Euclidean distances, it is able to consider a non-limited number of alternatives and criteria in the decision-making process. The purpose of this methodology is to first arrive at an ideal solution and a negative ideal solution, and then find a scenario which is nearest to the ideal solution and farthest from the negative ideal solution. The Weighted Normalized Decision Matrix is presented as follow:

$A=\left(a_{i j}\right)$ with $0 \leq i \leq n$ and $1 \leq j \leq m$ n: number of criteria and m: number of alternatives

$$
a_{i j}=w_{i j} x_{i j} / \sqrt{\sum_{i=1} x_{i j}^{2}}
$$

The Ideal solution and Negative Ideal solution:

$$
\begin{aligned}
& A^{+}=\left\{\left(\max _{i} a_{i j} \mid j \in J\right),\left(\min _{i} a_{i j} \mid j \in J^{\prime}\right) \mid i=1,2, \ldots, m\right\} \quad \text { (benifit) } \\
& A^{-}=\left\{\left(\min _{i} a_{i j} \mid j \in J\right),\left(\max _{i} a_{i j} \mid j \in J^{\prime}\right) \mid i=1,2, \ldots, m\right\}
\end{aligned}
$$

where $\mathbf{J}=\{\mathrm{j}=1,2, \ldots, \mathrm{n} \mid \mathrm{j}$ associated with benefit criteria $\}$,

$$
J^{\prime}=\{\mathrm{j}=1,2, \ldots, \mathrm{n} \mid \mathrm{j} \text { associated with cost criteria }\}
$$

Then after, we calculate the Ideal separation and Negative Ideal separation:

$$
\begin{aligned}
& S_{i}^{+}=\sqrt{\sum_{j}\left(A-A^{+}\right)^{2}} \\
& S_{i}^{-}=\sqrt{\sum_{j}\left(A-A^{-}\right)^{2}} \quad \text { With } \mathrm{i}=1,2, \ldots, \mathrm{n}
\end{aligned}
$$

And finally, the Relative Closeness to the Ideal Solution is calculated as follow:

$$
C_{i}^{*}=S_{i}^{-} /\left(S_{i}^{+}+S_{i}^{-}\right)
$$

\subsection{Concession function}

In the bilateral bargaining, the tow part of negotiation bargains about a set of issues related to a defined product. A win-win negotiation is a bargaining process aimed to find a mutually acceptable outcome that gives to both parties as much of what they want as possible. When the negotiation proposal/counterproposal cannot be accepted, a new counter-proposal is generated by the buyer or seller agent by conceding on one or more negotiation issues. The concession tactics involving time-dependent, resource-dependent and behaviour-dependent tactics introduced by Faratin et al. (1998) are applicable computational approaches for the composition of negotiation strategies reflecting agents' attitudes towards risks, time limits and resource availability. Time is the predominant factor used to decide how to make concession. The concession rate is a variable depending on time or the number of negotiation rounds. In the $t_{t h}(\mathrm{t}=1,2,3, \ldots)$ negotiation round, buyer agent b's concession rate for issue $I_{k}$ can be defined as:

$$
\alpha_{k}(t)= \begin{cases}b_{k}+\left(1-b_{k}\right)\left(\frac{t-1)}{t_{\max }}\right)^{1 / \gamma} & (0 \prec \gamma \leq 1) \\ \left.\exp \left(1-\left(\frac{(t-1)}{t_{\max }}\right)\right)^{\gamma} \ln \left(b_{k}\right)\right) & (\gamma \succ 1)\end{cases}
$$

The value of qualitative issue $I_{k}$ in the $t_{t h}(\mathrm{t}=1,2,3, \ldots)$ negotiation round at time $\mathrm{t}$, according to the value of $\alpha_{k}(t)$, with $0 \leq t \leq t_{\max }$ can be expressed using Eq. (3) and Eq. (4). The Eq. (3) is used for cost issue, and Eq. (4) for benefit issue: 
$I_{k}=\left\{\begin{array}{l}\min _{k}+\alpha_{k}(t)\left(\max _{k}-\min _{k}\right) \\ \min _{k}+\left(1-\alpha_{j}(t)\right)\left(\max _{k}-\min _{k}\right)\end{array}\right.$

Regarding the qualitative issue $I_{k}^{\prime}$, it can be expressed:

$$
I_{k}^{\prime}=\left\{\begin{array}{lcc}
V G & \text { for } & \alpha(t) \in] 0.875,1] \\
G & \text { for } & \alpha(t) \in] 0.625,0.875] \\
M & \text { for } & \alpha(t) \in] 0.375,0.625] \\
P & \text { for } & \alpha(t) \in] 0.125,0.375] \\
V P & \text { for } & \alpha(t) \in] 0,0.125]
\end{array}\right.
$$

The TFNs can be transformed into $0-1$ scale based on the graded mean integration representation method as shown in Eq (6):

$$
V\left(\tilde{I}_{k}\right)=\frac{1}{6}\left(m_{1}+4 m_{2}+m_{3}\right)
$$

\section{Application and results}

We adopted, in this section, a practical scenario from an industrial case study operating in the food sector. The main purpose of such adoption is to validate the applicability of the developed MAS approach using a real supply chain structure. We consider food manufacturer $\mathrm{M}$ (purchasing company) needs to procure a set of components denoted in the simulation by $\{\mathrm{P} 1, \mathrm{P} 2, \mathrm{P} 3, \mathrm{P} 4\}$, the relative requirements of each product is illustrated in Table 7 . Seven suppliers and three transportation provider are interested in the trading, represented by $\{\mathrm{S} 1, \mathrm{~S} 2, \mathrm{~S} 3, \mathrm{~S} 4, \mathrm{~S} 5, \mathrm{~S} 6, \mathrm{~S} 7\}$ and $\{\mathrm{T} 1, \mathrm{~T} 2, \mathrm{~T} 3\}$ respectively. The multi agent system is implemented in the JADE Platform, which is available as free software component. Firstly, manufacturer $M$ creates a shared agent platform with a main-container holding three lead agents: the DF (Directory Facilitator), AMS (Agent Management System) and RMA (Remote Monitoring Agent) which is in charge the registration and control functions for the whole platform. Fig. 8 portrays the agent location in the proposed system.

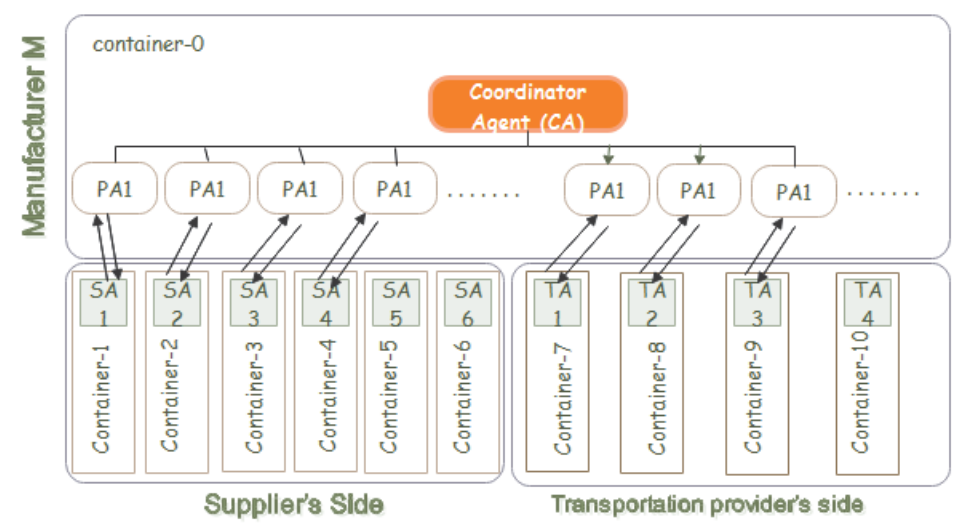

Fig. 8. Setting of the system agent

The settings of relative weights of the purchasing company and suppliers are assigned by the AHP method according to the Saaty matrix as shown in Table 2. Decision makers' performances on qualitative issues are represented by linguistic values \{Very poor, Poor, Medium, Good, Very good\}, the corresponding TFNs for the purchasing company and suppliers are listed in Table 3. Decision makers are designated to assign the negotiation issue value ranges as figured in Table 4, Table 5 and 
Table 6 according to their preferences on products. A value between 0 and 1 is assigned to the variable $\gamma$. Here, $\gamma=1$ for the purchasing company.

\section{Table 2}

Relative weights for negotiation criteria of purchasing company calculated by the AHP method

\begin{tabular}{ll}
\hline Criteria & Weight \\
\hline Price & $19.32 \%$ \\
Quality & $08.33 \%$ \\
Time & $72.35 \%$ \\
\hline
\end{tabular}

\section{Table 3}

Fuzzy number for qualitative issue

\begin{tabular}{ccc}
\hline Linguistic variable & Abbreviation & Fuzzy Number \\
\hline Very good & VG & $(0.75,1,1)$ \\
Good & $\mathrm{G}$ & $(0.25,0.75,1)$ \\
Medium & $\mathrm{M}$ & $(0.25,0.50,0.75)$ \\
Poor & $\mathrm{P}$ & $(0,0.25,0.50)$ \\
Very poor & $\mathrm{VP}$ & $(0,0,0.25)$ \\
\hline
\end{tabular}

\section{Table 4}

Value ranges \& transportation characteristics for negotiation issues of purchasing company

Configuration of parameters for negotiation process about product 1

purchasing company
Product characteristics

$\begin{array}{ccccc}\text { Price } & \text { Quality } & \text { Time } & \text { Price }(\$ / \mathrm{km}) & \text { Time } \\ {[100-160]} & {[\mathrm{P}-\mathrm{VG}]} & {[1-30]} & {[0,55-1,27]} & {[1-20]}\end{array}$

\section{Table 5}

Value spaces and relative weights for negotiation issues of suppliers about product 1

\begin{tabular}{|c|c|c|c|c|c|c|c|}
\hline \multirow{2}{*}{\multicolumn{2}{|c|}{$\begin{array}{l}\text { Configuration of parameters } \\
\text { for negotiation process about } \\
\text { product } 1(\mathrm{P} 1)\end{array}$}} & \multicolumn{3}{|c|}{ Product characteristics } & \multicolumn{3}{|c|}{ Conceding parameters } \\
\hline & & \multirow[t]{2}{*}{ Price } & \multirow[t]{2}{*}{ Quality } & \multirow[t]{2}{*}{ Time } & \multirow[t]{2}{*}{$T_{\max }$} & \multirow[t]{2}{*}{$b_{k}$} & \multirow[t]{2}{*}{$\lambda$} \\
\hline Suppliers & $\begin{array}{c}\text { Value } \\
\text { ranges/weight }\end{array}$ & & & & & & \\
\hline S1 & $\begin{array}{l}\text { Value } \\
\text { Weight }\end{array}$ & $\begin{array}{c}{[125-200]} \\
0.4\end{array}$ & $\begin{array}{c}\text { [VP-VG] } \\
0.3\end{array}$ & $\begin{array}{c}{[8-30]} \\
0.3\end{array}$ & 60 & 0,1 & 1 \\
\hline S2 & $\begin{array}{l}\text { Value } \\
\text { Weight }\end{array}$ & $\begin{array}{c}{[130-170]} \\
0.3\end{array}$ & $\begin{array}{c}{[\mathrm{M}-\mathrm{VG}]} \\
0.4\end{array}$ & $\begin{array}{c}{[5-20]} \\
0.3\end{array}$ & 60 & 0,1 & 0,23 \\
\hline S3 & $\begin{array}{l}\text { Value } \\
\text { Weight }\end{array}$ & $\begin{array}{c}{[100-180]} \\
0.4\end{array}$ & $\begin{array}{c}{[\mathrm{P}-\mathrm{M}]} \\
0.4\end{array}$ & $\begin{array}{c}{[10-20]} \\
0.2\end{array}$ & 60 & 0,1 & 1 \\
\hline S4 & $\begin{array}{l}\text { Value } \\
\text { Weight }\end{array}$ & $\begin{array}{c}{[110-120]} \\
0.15\end{array}$ & $\begin{array}{c}{[\mathrm{VP}-\mathrm{VG}]} \\
0.6\end{array}$ & $\begin{array}{c}{[9-30]} \\
0.25\end{array}$ & 60 & 0,1 & 0,82 \\
\hline S5 & $\begin{array}{l}\text { Value } \\
\text { Weight }\end{array}$ & $\begin{array}{c}{[90-140]} \\
0.2\end{array}$ & $\begin{array}{c}\text { [VP-G] } \\
0.4\end{array}$ & $\begin{array}{c}{[5-20]} \\
0.4\end{array}$ & 60 & 0,1 & 1 \\
\hline S6 & $\begin{array}{l}\text { Value } \\
\text { Weight }\end{array}$ & $\begin{array}{c}{[115-135]} \\
0.3\end{array}$ & $\begin{array}{c}{[\mathrm{VP}-\mathrm{G}]} \\
0.3\end{array}$ & $\begin{array}{c}{[2-30]} \\
0.4\end{array}$ & 60 & 0,1 & 0,23 \\
\hline S7 & $\begin{array}{l}\text { Value } \\
\text { Weight }\end{array}$ & $\begin{array}{c}{[114-124]} \\
0.6\end{array}$ & $\begin{array}{c}{[\mathrm{M}-\mathrm{VG}]} \\
0.2\end{array}$ & $\begin{array}{c}{[7-25]} \\
0.2\end{array}$ & 60 & 0,1 & 1 \\
\hline
\end{tabular}

Table 6

Value spaces and relative weights for negotiation issues of transportation providers about product 1

\begin{tabular}{ccccc}
\hline Transportation providers & Value ranges & Price & Delivery & Concession preference \\
\hline T1 & Value & {$[55-90]$} & {$[3-20]$} & 0,28 \\
& Weight & 0,7 & 0,3 & 0,23 \\
T 2 & Value & {$[80-100]$} & {$[1-15]$} & 1 \\
& Weight & 0,5 & 0,5 & 1 \\
& Value & {$[75-95]$} & $0,-18]$ & \\
\hline
\end{tabular}


Table 7

Requirement of product $1(\mathrm{P} 1)$

Requirement of product 1

\begin{tabular}{llll}
\hline Product & Temperature $\left({ }^{\circ} \mathrm{C}\right)$ & Humidity $(\%)$ & Incompatible products \\
\hline P1 & {$[0-6]$} & {$[80-90]$} & $\{$ OIL_\&_GAS, TOXIC, FLAMMABLE, \\
& & & CHEMICAL\&\&_FUELS $\}$ \\
\hline
\end{tabular}

\section{Phase 1: Supplier bilateral bargaining}

The different suppliers display their merchandise into the proposed platform, each product is presented as a vector of (Product name, price1, price2, quality, time1, time2, incompatible products list) according to the ontology SupplierOntology. We design by price1: the product cost including its transportation to the purchasing company warehouse, and price 2: the product cost without transportation. Accordingly, time 1 is the time needed to deliver the product to the buyer's warehouse and time 2 is the time for the product to be available for delivery.

Table 8 portrays the initial proposition of different suppliers in the first round. The proposed system is configured with negotiation parameters to conduct autonomously the bilateral bargaining (Table 5).

After receiving different offers from suppliers, corresponding PAs evaluate the proposal bid by bid, using the Eq (a) to (d) and calculate the separation from the ideal solution for each offer. The PA agent normalizes the proposal to generate the relative closeness to the ideal solution $\mathrm{S}^{*}$ and proposes the rank of different suppliers in the first round as dipected in Table 8. PA agent creates a counter proposal by generating negotiation values for each criteria price, quality and delivery time using Eq. (1) to Eq. (5). It is important to mention that the negotiation concerns the criteria (price 1, quality, time 1). In other words, suppliers ensure transportation of raw material to the purchasing company. Agents continue negotiating until reaching agreements or the negotiation deadline is reached.

\section{Table 8}

Proposition of the different suppliers in the first round and ranking for the different suppliers in the first round

\begin{tabular}{cccccccccccc}
\hline Suppliers & \multicolumn{2}{l}{ Supplier's proposals in the first round (proposal with transportation) } & & & \\
\cline { 2 - 12 } & Price & $\begin{array}{c}\text { V } \\
\text { (price) }\end{array}$ & Quality & $\begin{array}{c}\text { V } \\
\text { (Quality) }\end{array}$ & $\begin{array}{c}\text { Delivery } \\
\text { time }\end{array}$ & $\begin{array}{c}\text { V } \\
\text { (Time) }\end{array}$ & S+ & S- & S* & rank \\
\hline S1 & 150 & 0.0850 & $\mathrm{M}$ & 0.040 & 15 & 0.242 & 0.055 & 0.166 & 0.751 & 4 \\
S2 & 170 & 0.0963 & $\mathrm{G}$ & 0.057 & 17 & 0.274 & 0.086 & 0.140 & 0.618 & 5 \\
S3 & 130 & 0.0737 & $\mathrm{M}$ & 0.040 & 12 & 0.193 & 0.019 & 0.214 & 0.920 & 1 \\
S4 & 120 & 0.0680 & $\mathrm{P}$ & 0.020 & 25 & 0.403 & 0.213 & 0.033 & 0.134 & 7 \\
S5 & 125 & 0.0708 & $\mathrm{VP}$ & 0.003 & 12 & 0.193 & 0.054 & 0.211 & 0.797 & 3 \\
S6 & 115 & 0.0652 & $\mathrm{P}$ & 0.020 & 20 & 0.322 & 0.134 & 0.088 & 0.396 & 6 \\
S7 & 114 & 0.0646 & $\mathrm{M}$ & 0.040 & 13 & 0.210 & 0.023 & 0.199 & 0.896 & 2 \\
\hline
\end{tabular}

\section{Table 9}

Proposition of the different suppliers (poroposition without transportation) and ranking for the different suppliers in the first round

\begin{tabular}{|c|c|c|c|c|c|c|c|c|c|c|}
\hline Suppliers & Price & $\begin{array}{c}\mathrm{V} \\
\text { (price) }\end{array}$ & Quality & $\begin{array}{c}\mathrm{V} \\
\text { (Quality) }\end{array}$ & Delivery time & $\begin{array}{c}\mathrm{V} \\
\text { (Time) }\end{array}$ & $\mathbf{S +}$ & S- & $\mathbf{S *}$ & rank \\
\hline S1 & 40 & 0.042 & M & 0.040 & 3 & 0.136 & 0.017 & 0.280 & 0.944 & 1 \\
\hline S2 & 55 & 0.058 & $\mathbf{G}$ & 0.057 & 7 & 0.317 & 0.182 & 0.113 & 0.384 & 5 \\
\hline S3 & 90 & 0.094 & M & 0.040 & 8 & 0.362 & 0.233 & 0.058 & 0.201 & 6 \\
\hline S4 & 80 & 0.084 & $\mathbf{P}$ & 0.020 & 9 & 0.407 & 0.277 & 0.023 & 0.076 & 7 \\
\hline S5 & 95 & 0.099 & VP & 0.003 & 5 & 0.226 & 0.120 & 0.181 & 0.602 & 4 \\
\hline S6 & 80 & 0.084 & $\mathbf{P}$ & 0.020 & 3 & 0.136 & 0.056 & 0.273 & 0.831 & 2 \\
\hline S7 & 45 & 0.047 & $\mathbf{M}$ & 0.040 & 4 & 0.181 & 0.049 & 0.235 & 0.829 & 3 \\
\hline
\end{tabular}


Then after, the PA agent sends the negotiation results to the $\mathrm{CA}$ agent, the information contains the offer including the transportation cost (table 8) and the offer without (table 9). Afterward, The CA agent creates TpAs for each TAs involved in the trading and assigns suppliers how are well ranked first. Each transportation provider is in charge of transporting raw material from two suppliers or more.

\section{Phase 2: pre-selection of transportation providers}

This phase aims to restrict the list of transportation providers involved in the MAS according to the required conditions for the selected suppliers. This restricts the contract manufacturer to select its transporters from preapproved list of transportation providers. This means that the purchasing company cannot select any transporter outside of this list. Therefore, the purchasing company will need to improve the performance of the selected transportation providers on a continuous manner. For this purpose, the transportation Ontology is initialized. The figure 10 shows the instances of some Concept through the reasoning process.

The objective of this phase is to affect suppliers involved to the transportation providers respecting the required condition of transportation.

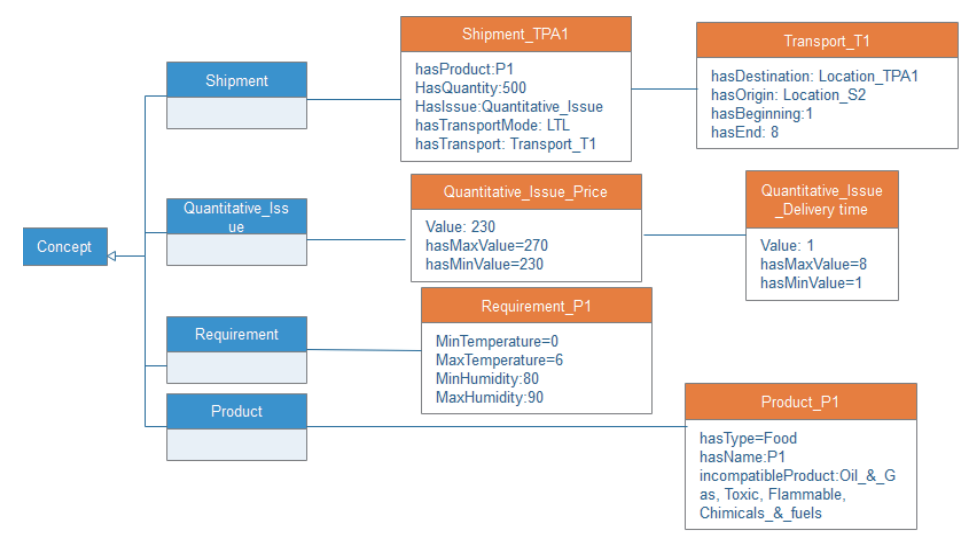

Fig. 10. Instantiation of concepts in the transportation ontology

\section{Phase 3: transportation provider bilateral bargaining}

In this stage, transport product Agent TpA deals with hauliers to ensure the transportation. The transportation ontology gathers the information required to arrange with transportation providers and presents the criteria required by suppliers to carry the merchandise in optimal condition.

Table 10

Proposition of different transportation provider

\begin{tabular}{ccccc}
\hline \multirow{2}{*}{$\begin{array}{c}\text { Transportation } \\
\text { providers }\end{array}$} & \multicolumn{2}{c}{ Transportation provider proposition } & & Price \\
\cline { 2 - 5 } & Source & Destination & 130 & Delivery time \\
\hline T1 & S1, S6, S7 & Purchasing company & 120 & 7 \\
T2 & S5, S6 & Purchasing company & 110 & 4 \\
T3 & S1, S2 & Purchasing company & & 7 \\
\hline
\end{tabular}

On the same basis, agents continue negotiating until reaching agreements or the negotiation deadline is reached. To close the first round, PA and TpA send the counter-proposal to the supplier and transportation provider successively.

\section{Phase 4: supplier and transportation provider combination}

This article considers the integrated approach that simultaneously addresses the problem of supplier selection and transportation provider selection to attain the optimal combination in term of transporting the merchandise from suppliers to the manufacturer warehouse, the main issue studied thereupon is to decide either to arrange the transportation by the supplier or outsource it to a transportation provider. 
After the bargaining process had been finalized, the results are received by the CA agent who performs the analysis and indicates which choice is better and update the database of suppliers and transportation providers to be part of the company's supply. The table 11 shows a dashboard for the two cases handled in this article: suppliers ensure the transportation by its own hauliers or outsource the transportation to a company of transport.

\section{Table 11}

The final decision either to outsource the transportation or assure it by suppliers

\begin{tabular}{|c|c|c|c|c|c|c|c|c|c|c|c|c|}
\hline \multirow[b]{2}{*}{ Suppliers } & \multicolumn{5}{|c|}{ procurement with transportation } & \multicolumn{3}{|c|}{ procurement without transportation } & \multicolumn{4}{|c|}{ Transportation provider } \\
\hline & Price & Quality & Time & $\begin{array}{c}\text { Bid } \\
\text { utility }\end{array}$ & $\begin{array}{c}\text { Solution } \\
\text { Utility }\end{array}$ & Price 2 & Quality & Time 2 & Transporters & Price & $\begin{array}{c}\text { Delivery } \\
\text { time }\end{array}$ & $\begin{array}{c}\text { Solution } \\
\text { Utility }\end{array}$ \\
\hline S1 & 150 & M & 15 & 0.751 & \multirow{3}{*}{0.684} & 40 & M & 3 & \multirow{2}{*}{$\mathrm{T} 3$} & \multirow{2}{*}{110} & \multirow{2}{*}{4} & \multirow{2}{*}{1} \\
\hline S2 & 170 & G & 17 & 0.618 & & 55 & $\mathbf{G}$ & 7 & & & & \\
\hline S3 & 130 & $\mathbf{M}$ & 12 & 0.920 & & 90 & $\mathbf{M}$ & 8 & \multirow{3}{*}{$\mathrm{T} 1$} & \multirow{3}{*}{130} & \multirow{3}{*}{5} & \multirow{3}{*}{$\mathbf{0}$} \\
\hline S4 & 120 & $\mathbf{P}$ & 25 & 0.134 & \multirow{3}{*}{0.650} & 80 & $\mathbf{P}$ & 9 & & & & \\
\hline S7 & 114 & M & 13 & 0.896 & & 45 & $\mathbf{M}$ & 4 & & & & \\
\hline S5 & 125 & $\mathbf{V P}$ & 12 & 0.797 & & 95 & VP & 5 & \multirow{2}{*}{$\mathrm{T} 2$} & \multirow{2}{*}{120} & \multirow{2}{*}{7} & \multirow{2}{*}{0.850} \\
\hline S6 & 115 & $\mathbf{P}$ & 20 & 0.396 & $\mathbf{0 . 5 9 7}$ & 80 & 8 & 3 & & & & \\
\hline
\end{tabular}

We mainly present in this work the role and the impact of transport on the total cost of raw material. As illustrated in the table 11, it's benefic in the case of suppliers S1 and S2 to outsource the transportation to the transporter T3, the same case as S5 and S6. However, for suppliers S3, S4 and S7 it's profitable to ensure the transportation by their own trucks.

\section{Conclusion and perspectives}

In this paper, we have been particularly interested in the problem of supplier selection and treat transport provider selection explicitly and simultaneously, by using multi agent decision making model. Our proposed decision aiding model is helpful in term of dealing an integrated decision between procurement department and transport department. Firstly, we have proposed the MAS supporting the negotiation model for supplier selection and transportation provider selection. Secondly, we have elaborated the negotiation protocol and decision-making methods relating to the negotiation model for the product supplier selection and transportation provider selection. Thirdly, the identification of potential suppliers and transportation providers has been reached using the hybrid AHP-TOPSIS method. Finally, the function and effectiveness of the agent-based negotiation model for product supplier selection and transportation provider selection has been established. The negotiation scheme and the ontological knowledge organization for the negotiation between buyer side and seller side have been implemented using PROTEGEE. In the future, further efforts will be done on the combination of the procurement process and transportation process to consider further criteria especially environmental criteria to support the sustainable development goals. Correspondingly, we focus, in the future, on the integration of other technologies, beside agent technology, such as IoT and cloud computing to synchronize the information flow and improve the tracking of respect requirement.

\section{References}

Achatbi, I., Amechnoue, K., \& Allouch, S. A. (2017, April). An Ontology Based Approach to Organize Supplier and Transportation Provider Selection Negotiation in Multi-agent System Model. In International Conference on Advanced Information Technology, Services and Systems (pp. 129-137). Springer, Cham.

Cao, M., Luo, X., Luo, X. R., \& Dai, X. (2015). Automated negotiation for e-commerce decision making: a goal deliberated agent architecture for multi-strategy selection. Decision Support Systems, 73, 1-14.

Chai, J., Liu, J. N., \& Ngai, E. W. (2013). Application of decision-making techniques in supplier selection: A systematic review of literature. Expert systems with applications, 40(10), 3872-3885.

Chan, F. T., \& Chan, H. K. (2010). An AHP model for selection of suppliers in the fast changing fashion market. The International Journal of Advanced Manufacturing Technology, 51(9-12), 1195-1207.

Chen, Y. M., \& Huang, P. N. (2009). Agent-based bilateral multi-issue negotiation scheme for e-market 
transactions. Applied Soft Computing, 9(3), 1057-1067.

Chiang, C., \& Chiang, W. C. (1996). Reducing inventory costs by order splitting in the sole sourcing environment. Journal of the Operational Research Society, 47(3), 446-456.

Choi, S. P. M., Liu, J., \& Chan, S. P. (2001). A genetic agent-based negotiation system. Computer Networks, 37(2), 195-204.

Choy, K. L., \& Lee, W. B. (2002). A generic tool for the selection and management of supplier relationships in an outsourced manufacturing environment: the application of case based reasoning. Logistics Information Management.

Choy, K. L., \& Lee, W. B. (2003). A generic supplier management tool for outsourcing manufacturing. Supply Chain Management: An International Journal, 8(2), 140-154.

Choy, K. L., Lee, W. B., Lau, H. C., \& Choy, L. C. (2005). A knowledge-based supplier intelligence retrieval system for outsource manufacturing. Knowledge-based Systems, 18(1), 1-17.

De Boer, L., Labro, E., \& Morlacchi, P. (2001). A review of methods supporting supplier selection. European Journal of Purchasing \& Supply Management, 7(2), 75-89.

Ding, H., Benyoucef, L., \& Xie, X. (2005). A simulation optimization methodology for supplier selection problem. International Journal of Computer Integrated Manufacturing, 18(2-3), 210-224..

Faratin, P., Sierra, C., \& Jennings, N. R. (1998). Negotiation decision functions for autonomous agents. Robotics and Autonomous Systems, 24(3-4), 159-182.

GüNeri, A. F., Ertay, T., \& YüCel, A. (2011). An approach based on ANFIS input selection and modeling for supplier selection problem. Expert Systems with Applications, 38(12), 14907-14917..

Gencer, C., \& Gürpinar, D. (2007). Analytic network process in supplier selection: A case study in an electronic firm. Applied mathematical modelling, 31(11), 2475-2486.

Ghadimi, P., Toosi, F. G., \& Heavey, C. (2018). A multi-agent systems approach for sustainable supplier selection and order allocation in a partnership supply chain. European Journal of Operational Research, 269(1), 286-301.

Giovannucci, A., Rodríguez-Aguilar, J. A., Reyes, A., Noria, F. X., \& Cerquides, J. (2008). Enacting agentbased services for automated procurement. Engineering Applications of Artificial Intelligence, 21(2), 183-199.

Giret, A., Trentesaux, D., Salido, M. A., Garcia, E., \& Adam, E. (2018). A holonic multi-agent methodology to design sustainable intelligent manufacturing control systems. Journal of Cleaner Production, 167, $1370-1386$.

Ho, W., Xu, X., \& Dey, P. K. (2010). Multi-criteria decision making approaches for supplier evaluation and selection: A literature review. European Journal of Operational Research, 202(1), 16-24.

Hong, J. D., \& Hayya, J. C. (1992). Just-in-time purchasing: single or multiple sourcing?. International Journal of Production Economics, 27(2), 175-181.

Huang, S. H., \& Keskar, H. (2007). Comprehensive and configurable metrics for supplier selection. International journal of production economics, 105(2), 510-523.

Ishizaka, A., Pearman, C., \& Nemery, P. (2012). AHPSort: an AHP-based method for sorting problems. International Journal of Production Research, 50(17), 4767-4784.

Jonker, C. M., \& Treur, J. (2007). An agent architecture for multi-attribute negotiation. In IJCAI International Joint Conference on Artificial Intelligence (Vol. 15, pp. 1195-1201).

Lin, C., Chen, C., \& Ting, Y. (2011). Expert Systems with Applications An ERP model for supplier selection in electronics industry. Expert Systems With Applications, 38(3), 1760-1765.

Lin, F. ren, \& Lin, Y. yu. (2006). Integrating multi-agent negotiation to resolve constraints in fulfilling supply chain orders. Electronic Commerce Research and Applications, 5(4), 313-322.

Mendoza, A., \& Ventura, J. A. (2013). Modeling actual transportation costs in supplier selection and order quantity allocation decisions. Operational Research, 13(1), 5-25.

Narayanan, V., \& Jennings, N. R. (2005). An adaptive bilateral negotiation model for e- commerce settings. In Proceedings - Seventh IEEE International Conference on E-Commerce Technology, CEC 2005 (Vol. 2005, pp. 34-41).

Nejma, M., Zair, F., Cherkaoui, A., \& Fourka, M. (2019). Advanced supplier selection: A hybrid multiagent negotiation protocol supporting supply chain dyadic collaboration. Decision Science Letters, 8(2), $175-192$.

Florez-Lopez, R. (2007). Strategic supplier selection in the added-value perspective: A CI 
approach. Information Sciences, 177(5), 1169-1179.

Ram, G. (1999). Managing supply chain inventories: A multiple retailer, one warehouse, multiple supplier model. International Journal of Production Economics, 59(1-3), 341-354.

Renna, P., \& Argoneto, P. (2010). Production planning and automated negotiation for SMEs: An agent based e-procurement application. International Journal of Production Economics, 127(1), 73-84.

Sadigh, B. L., Unver, H. O., Nikghadam, S., Dogdu, E., Ozbayoglu, A. M., \& Kilic, S. E. (2017). An ontology-based multi-agent virtual enterprise system (OMAVE): part 1: domain model 1 ing and rule management. International Journal of Computer Integrated Manufacturing, 30(2-3), 320-343.

Sanayei, A., Farid Mousavi, S., \& Yazdankhah, A. (2010). Group decision making process for supplier selection with VIKOR under fuzzy environment. Expert Systems with Applications, 37(1), 24-30.

Sarkis, J., \& Talluri, S. (2002). A Model for Strategic Supplier Selection. The Journal of Supply Chain Management, 38(1), 18-28.

Stank, T. P., \& Goldsby, T. J. (2000a). A framework for transportation decision making in an integrated supply chain. Supply Chain Management: An International Journal, 5(2), 71-78.

Sachan, A., \& Datta, S. (2005). Review of supply chain management and logistics research. International Journal of Physical Distribution \& Logistics Management.

Swenseth, S. R., \& Godfrey, M. R. (2002). Incorporating transportation costs into inventory replenishment decisions. International Journal of Production Economics, 77(2), 113-130.

Talluri, S. (2002). A buyer-seller game model for selection and negotiation of purchasing bids. European Journal of Operational Research, 143(1), 171-180.

Talluri S., \& Baker R.C. (2002). A multi-phase mathematical programming approach for effective supply chain design. European Journal of Operational Research, 141, 544-558.

Tamma, V., Phelps, S., Dickinson, I., \& Wooldridge, M. (2005). Ontologies for supporting negotiation in e-commerce. Engineering Applications of Artificial Intelligence, 18(2), 223-236.

Thomas, D. J., \& Griffin, P. M. (1996). Coordinated supply chain management. European journal of operational research, 94(1), 1-15.

Tyworth, J. E. (1991). The inventory theoretic approach in transportation selection models: a critical review. Logistics and Transportation Review, 27(4), 299.

Wang, G., Wong, T. N., \& Wang, X. (2013). An ontology based approach to organize multi-agent assisted supply chain negotiations. Computers \& Industrial Engineering, 65(1), 2-15.

Wang, G., Wong, T. N., \& Wang, X. (2014). A hybrid multi-agent negotiation protocol supporting agent mobility in virtual enterprises. Information Sciences, 282, 1-14.

Wang, M., Wang, H., Vogel, D., Kumar, K., \& Chiu, D. K. (2009). Agent-based negotiation and decision making for dynamic supply chain formation. Engineering Applications of Artificial Intelligence, 22(7), 1046-1055.

Wang, X., Wong, T. N., \& Wang, G. (2012). An ontological intelligent agent platform to establish an ecological virtual enterprise. Expert Systems with Applications, 39(8), 7050-7061.

Wooldridge, M., \& Jennings, N. R. (1995). Intelligent agents: Theory and practice. The Knowledge Engineering Review, 10(2), 115-152.

$\mathrm{Wu}$, T., \& Blackhurst, J. (2009). Supplier evaluation and selection: an augmented DEA approach. International Journal of Production Research, 47(16), 4593-4608.

$\mathrm{Yu}, \mathrm{C}$., \& Wong, T. N. (2015). A multi-agent architecture for multi-product supplier selection in consideration of the synergy between products. International Journal of Production Research, 53(20), 6059-6082.

Yu, C., \& Wong, T. N. (2015). An agent-based negotiation model for supplier selection of multiple products with synergy effect. Expert Systems with Applications, 42(1), 223-237.

$\mathrm{Yu}$, C., Zhao, W., \& Li, M. (2019). An integrated sustainable supplier selection approach using compensatory and non-compensatory decision methods. Kybernetes.

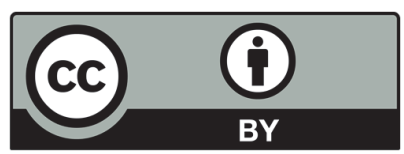

(C) 2020 by the authors; licensee Growing Science, Canada. This is an open access article distributed under the terms and conditions of the Creative Commons Attribution (CC-BY) license (http://creativecommons.org/licenses/by/4.0/). 